\title{
Crossed ladders and power means
}

\author{
Ralph Høibakk and Dag Lukkassen
}

Ralph Høibakk obtained his Master degree in physics from the Norwegian Institute of Technology in 1962. He is now a part-time professor at Narvik University College within Enterprise Development.

Dag Lukkassen obtained his Dr. Scient. degree in mathematics from Troms $\varnothing$ University in 1996. He is a full professor of mathematics at Narvik University College since 2000. His main field is partial differential equations and their applications.

The so-called crossed ladders problem, of unknown origin, has been discussed in the literature at least since 1895 (see [3, pp. 62-64]). Consider two ladders leaning against two vertical walls at heights $a$ and $b$ above the floor and with distance $d$ between the walls (see Fig. 1). These ladders cross each other at a point with distance $c$ above the floor. The problem is devoted to the determination of various types of relations between the above quantities. The beauty of the problem is that at first it looks very simple, but one soon realizes that many aspects of it may be rather difficult, as seen from the discussions in e.g. [1], [5], [6], and [7]. In this paper, however, we will focus on some simple aspects of the crossed ladders problem which, as far as we know, have not been offered much attention in the literature, namely its relation to the basic power means.

Ausgehend von den bekannten Mitteln zweier positiver reeller Zahlen $a, b$, nämlich dem arithmetischen, dem geometrischen und dem harmonischen Mittel, wird das Potenzmittel $P_{k}(a, b)$ der Ordnung $k(k \in \mathbb{Z}, k \neq 0)$ durch $P_{k}(a, b)=\left(a^{k} / 2+b^{k} / 2\right)^{1 / k}$ definiert (im Fall $k=0$ setzt man $P_{0}(a, b)=\sqrt{a b}$ ). In dem nachfolgenden Beitrag stellen die Autoren einen Zusammenhang zwischen den Potenzmitteln $P_{k}(a, b)$ und dem Problem sich kreuzender Leitern her. Bei diesem Problem werden zwei Leitern betrachtet, die zwischen zwei Wänden derart aufgestellt werden, dass die eine Leiter am Fussboden der ersten Wand angelegt ist und die zweite Wand in der Höhe $b$ (vom Fussboden aus gemessen) berührt; entsprechend wird die zweite Leiter an der zweiten Wand angelegt und berührt die erste Wand in Höhe $a$. In dieser Konfiguration lassen sich nun verschiedene Grössen identifizieren und in Abhängigkeit von $a$ und $b$ ausdrücken. Beispielsweise stellt man fest, dass die Höhe des Punktes, in dem sich die beiden Leitern kreuzen, durch das halbe harmonische Mittel von $a$ und $b$ gegeben ist. 


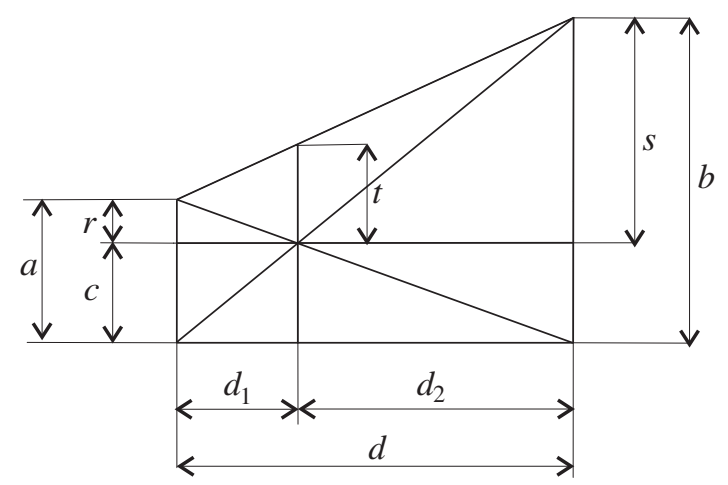

Fig. 1 The crossed ladders problem

Power means have fascinated mathematicians since antiquity. For two positive numbers $a$ and $b$ the power mean $P_{k}$ (with equal weights) of order $k$ is defined by

$$
P_{k}=\left\{\begin{array}{cc}
\left(\frac{a^{k}+b^{k}}{2}\right)^{\frac{1}{k}}, & \text { if } k \neq 0 \\
\sqrt{a b}, & \text { if } k=0
\end{array}\right.
$$

The most common power means are the arithmetic mean $A=P_{1}$, the geometric mean $G=P_{0}$ and the harmonic mean $H=P_{-1}$, given by the formulae

$$
A=\frac{a+b}{2}, \quad G=\sqrt{a b}, \quad H=\frac{2 a b}{a+b},
$$

respectively. By using the inequality $a^{2}+b^{2} \geq 2 a b$, which follows by the fact that $(a-b)^{2} \geq 0$, it is easily seen that $H \leq G \leq A$. More generally, it follows by the Jensen inequality that $P_{k} \leq P_{l}$ if $k \leq l$, and equality occurs only if $k=l$. For more general information on means, we recommend the books [2] and [4].

By considering similar triangles in Fig. 1, we see that

$$
d_{1}=\frac{d c}{b}
$$

and

$$
d_{2}=\frac{d c}{a}
$$

which, combined with $d=d_{1}+d_{2}$, imply

$$
c=\frac{b a}{a+b}
$$

By similar triangles we also obtain that $(b-t-c) / d_{2}=(b-a) / d$, and together with (1) and (3) we find that $t=c$. This gives us the interesting information that the length 
$c+t$ of the vertical line segment passing through the intersection of the ladders actually is the harmonic mean of $a$ and $b$.

Using other similar triangles we obtain the relations $r / d_{1}=c / d_{2}$ and $s / d_{2}=c / d_{1}$, from which we deduce that $t=c=\sqrt{r s}$. This shows another interesting property, namely that the length $t$ is equal to the geometric mean of the vertical lengths $r$ and $s$ in Fig. 1.

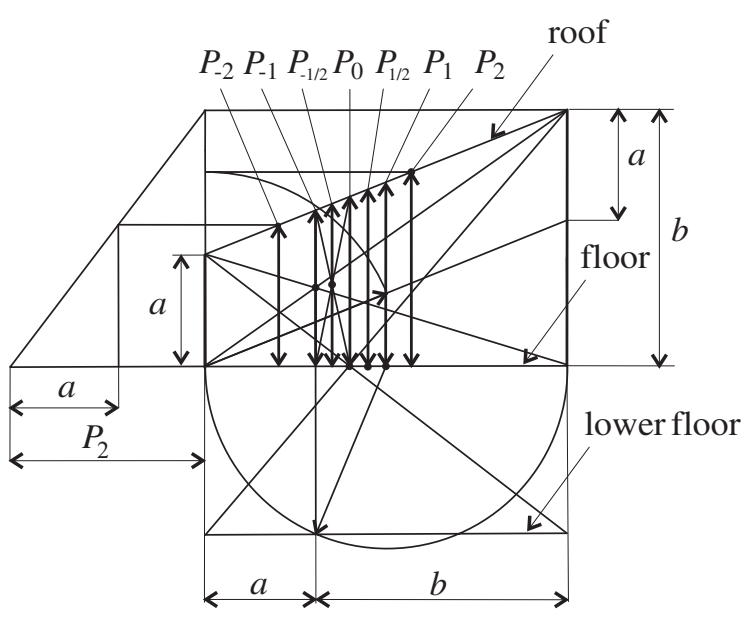

Fig. 2 Interpretation of the power means $P_{-2}, P_{-1}, P_{-1 / 2}, P_{0}$, $P_{1 / 2}, P_{1}$ and $P_{2}$ as lengths of (bold) vertical lines

Note that when $d=a+b$ we obtain from (1), (2), and (3) that $d_{1}=a$ and $d_{2}=b$. On the basis of the above simple observations and other geometrical observations we can easily interpret the power means $P_{-2}, P_{-1}, P_{-1 / 2}, P_{0}, P_{1 / 2}, P_{1}$ and $P_{2}$ of two given positive values $a$ and $b$ as lengths of the vertical (bold) lines constructed as illustrated in Fig. 2.

First we draw the two walls of lengths $a$ and $b$, connected by a floor of length $d=a+b$ and a roof connecting the top of the two walls. The geometrical interpretation of $P_{2}$ illustrated in Fig. 2 follows by observing that the length of the roof is $2 P_{2}$.

The arithmetic mean $A=P_{1}$ certainly corresponds to the vertical distance between the roof and the floor at the midpoint between the walls, and the harmonic mean corresponds to the distance between the roof and the floor at distance $d_{1}=a$ from the left wall.

Next, in order to find the geometric mean $G=P_{0}$ we extend the walls downwards until the new crossed ladders (with endpoints on the lower floor) intersect with the upper floor. The lower floor is found by observing that it contains the intersection between the lower half-circle on Fig. 2 (with center at the midpoint of the upper floor and radius equal to $(a+b) / 2)$ and the vertical line at distance $d_{1}=a$ from the left wall. The geometric mean then corresponds to the vertical length between the roof and the floor at the intersection between the new crossed ladders.

The construction of the length $P_{-2}$ follows by observing the simple relation $P_{-k} P_{k}=a b$ (i.e. $P_{-2} / a=b / P_{2}$ ) and then using the similar triangles to the left in Fig. 2. 
The remaining power means are found from observing the striking facts that $P_{1 / 2}$ is the arithmetic mean of $P_{0}$ and $P_{1}$ and that $P_{-1 / 2}$ is the harmonic mean of $P_{0}$ and $P_{-1}$. Hence, $P_{1 / 2}$ corresponds to the distance between the roof and floor at the midpoint between the walls of heights $P_{0}$ and $P_{1}$, and $P_{-1 / 2}$ corresponds to the vertical length of the line between the roof and the floor going through the intersection between the crossed ladders leaning against two vertical walls of heights $P_{0}$ and $P_{-1}$.

In addition to the above power means we may certainly also interpret $P_{-\infty}=a$ and $P_{\infty}=b$ as the heights of the two walls.

\section{Acknowledgement}

We are grateful to the anonymous reviewer for helping us to improve the presentation of this paper.

\section{References}

[1] Bennett, A.A.: E 433 (1940, 487). Amer. Math. Monthly (1941), 268-269.

[2] Bullen, P.S.; Mitrinovic, D.S.; Vasic, P.M.: Means and their inequalities. D. Reidel Publishing Company, Dordrecht 1988

[3] Gardner, M.: Mathematical Circus: More Puzzles, Games, Paradoxes and Other Mathematical Entertainments from Scientific American. Knopf, New York 1979.

[4] Hardy, G.H.; Littlewood, J.E.; Pólya, G.: Inequalities. Cambridge University Press, 1934, 1978.

[5] Nelson, H.L.: The Two Ladders. J. Recreational Math. 11 (1979/80) 4, 312-314.

[6] Sutcliffe, A.: Complete Solution of the Ladder Problem in Integers. Math. Gaz. 47 (1963), 133-136.

[7] Tester, H.E.: Note 3036. Math. Gaz. 46 (1962), 313.

Ralph Høibakk, Dag Lukkassen

Narvik University College

N-8505 Narvik, Norway

e-mail: Dag.Lukkassen@hin.no 